\title{
LOS PROCESOS IMAGINATIVOS EN LOS DIBUJOS DE NIÑOS Y ADOLESCENTES
}

\section{IMAGINATIVE PROCESSES IN THE DRAWINGS OF CHILDREN AND ADOLESCENTS}

Analía Wald

E-mail para correspondência: awald@psi.uba.ar

\begin{abstract}
RESUMEN
El artículo presenta algunos resultados y conclusiones de la tesis doctoral de la autora "Características de los procesos imaginativos en los dibujos de niños con problemas de aprendizaje" ${ }^{1}$ (2015) enmarcada en el Programa de Investigación de

1 La investigación "Transformations in imaginative processes in drawings of children with learning difficulties" se llevó a cabo con subsidio del Reserach Advisory Board de la Asociación Psicoanalítica Internacional.
\end{abstract}


la Cátedra de Psicopedagogía Clínica de la Facultad de Psicología de la Universidad de Buenos Aires. Se centra en una conceptualización psicoanalítica de los procesos imaginativos y un modelo de análisis de dichos procesos en las producciones gráficas de niños y adolescentes. La investigación involucró un diseño cualitativo cuyo objetivo general fue elaborar un modelo teórico-clínico de análisis de los dibujos de niños con problemas de aprendizaje para caracterizar restricciones específicas en los procesos imaginativos. El modelo implica la construcción de indicadores en el material gráfico y de hipótesis de mediación entre los indicadores y las dimensiones psíquicas propuestas. Se definieron los ejes centrales de los procesos imaginativos y se construyeron categorías para analizar la producción gráfica incorporando referencias semióticas. Se analizaron las producciones gráficas (Dibujo libre y Dibujo de la Familia Kinética) de dieciséis niños consultantes en su diagnóstico inicial. Se describen modalidades predominantes desde el punto de vista dinámico y se conceptualizan los procesos imaginativos en sus relaciones con la simbolización y el aprendizaje.

Palabras-clave: simbolización, aprendizaje, psicoanálisis, grafismo, infancia.

\section{ABSTRACT}

The article presents developments of the author's doctoral thesis "Imaginative processes in graphic productions of children and adolescents with learning difficulties" (2015) carried out within the Research Programme of the Chair of Psycho-pedagogical Clinic, Faculty of Psychology, University of Buenos Aires. A psychoanalytic conceptualization of imaginative processes together with a model for the analysis of graphic productions of children and adolescents is provided. The research involved a qualitative design whose overall objective was to develop a theoretical and clinical model for the analysis of drawings of children with learning problems in order to characterize specific restrictions in the imaginative processes. The model involves the construction of indicators in drawings and mediation hypothesis between indicators and psychic dimensions. Core axes of imaginative processes were defined and categories incorporating semiotic references were built to analyze graphic productions. Free Drawing and Kinetic-Family Drawing of sixteen children at initial diagnosis were analyzed. Predominant dynamic modalities were described and imaginative processes were conceptualized in relation to symbolization and learning.

Keywords: symbolization, learning, psychoanalysis, graphism.

\section{INTRODUCCIÓN}

El propósito de este trabajo es presentar una conceptualización de los procesos imaginativos y sus modalidades restrictivas en niños con problemas de aprendizaje, conjuntamente con un modelo de abordaje clínico de dichos procesos a 
través de la producción gráfica. Estos desarrollos son aportes de la tesis doctoral de la autora (2015) vinculada al Programa de Investigación de la Cátedra de Psicopedagogía Clínica de la Facultad de Psicología de la Universidad de Buenos Aires.

La necesidad de profundizar en el estudio de la imaginación en psicoanálisis surgió a partir del trabajo psicoanalítico con niños y adolescentes con problemas de aprendizaje en el marco de un programa clínico que asiste a niños y jóvenes derivados por los equipos de orientación escolar de la ciudad de Buenos Aires ${ }^{2}$.

El abordaje que se propone entiende el aprendizaje como un proceso complejo vinculado al pensamiento autónomo y a la implicación creativa del sujeto deseante en un movimiento de búsqueda de alternativas de placer. Así, la imaginación resulta un recurso esencial para la inserción del niño en el sistema educativo con capacidad crítica y con un proyecto de transformación.

Las restricciones imaginativas de niños y jóvenes con problemas de aprendizaje quedan plasmadas en sus producciones simbólicas, es decir, en sus dibujos, escrituras, lecturas y narraciones (Schlemenson, 2010). El análisis de las características que presentan los procesos imaginativos en las producciones simbólicas de los niños y adolescentes, intenta refinar las estrategias de intervención clínica que, lejos de consolidar formas rígidas o sobreadaptadas, faciliten las condiciones para potenciar la imaginación.

Luego de definir los ejes centrales para el análisis de los procesos imaginativos se procedió a la construcción de categorías para analizar la producción gráfica. La investigación cualitativa se caracteriza por la construcción de un modelo teórico como vía de significación de la información producida, la cual no está fragmentada en resultados parciales asociados a los instrumentos sino que se integra en un sistema cuya inteligibilidad es producida por el investigador. Las categorías de análisis constituyen construcciones complejas detrás de las cuales existen múltiples referentes empíricos que confluyen como fundamento de la construcción teórica del investigador (González Rey, 2006).

Se analizaron el Dibujo libre y el Dibujo de la Familia Kinética (Burns y Kaufman, 1978) realizados por los niños en su diagnóstico inicial ${ }^{3}$. Se describie-

2 Programa de Asistencia Psicopedagógica. Secretaría de Extensión Universitaria. Facultad de Psicología. Universidad de Buenos Aires.

3 En función de la estrategia cualitativa se analizaron dibujos de dieciseis niños en escolaridad primaria consultantes del programa asistencial. En los estudios de casos que tienen por finalidad la construcción de teoría, cada caso nos muestra algo nuevo y distintivo, ya sea que se pueda encuadrar en la teoría existente o que ésta requiera modificaciones "para hacerle lugar". La significación de los casos es una cuestión teórica y no estadística porque el objetivo prioritario es la construcción de un modelo más que la caracterización de la población objeto de la investigación (Stiles, 2009). 
ron modalidades predominantes desde el punto de vista dinámico y se conceptualizaron los procesos imaginativos en sus relaciones con la simbolización y el aprendizaje.

\section{LA IMAGINACIÓN}

La pregunta por los modos en que la imaginación interviene en la construcción de nuestro conocimiento del mundo y de nosotros mismos ha tenido diferentes respuestas en la historia del pensamiento filosófico y psicoanalítico. ¿Es una actividad que sólo está al servicio del placer propio y singular, o puede orientarse al conocimiento y la realidad?

A partir del siglo XVIII cambia el concepto de imaginación. El giro moderno hacia nuevos modelos de subjetividad jerarquiza el poder de la imaginación de "configurar" la verdad, más que de representarla. Según Richard Kearney (1998), el poder creativo de la imaginación se deriva de la triple descripción como facultas formandi, facultad que forma imágenes del presente, como facultas imaginandi que recuerda imágenes del pasado y como facultas praevidendi, que anticipa imágenes del futuro.

Para Lev Vygotsky (2003), la imaginación está implicada en toda actividad humana que crea nuevas imágenes o acciones. El mundo que nos rodea es producto de la imaginación y la creación humana. Ricoeur (2010) critica al modelo representacional de la imagen como simple negación de la realidad perceptual. La imaginación es un agente central en la creación de sentido en y a través del lenguaje. La imagen no es reunión de restos perceptuales sino reunión de sentidos emergentes.

Diversos autores plantean la cuestión del afecto como estrato mínimo de la función representativa. Para Kristeva (1997), si bien lo imaginario se expresa a través del discurso, deriva de un orden semiótico de afectos que no pueden ser entendidos con un modelo exclusivamente lingüístico. Según Castoriadis, la imaginación radical traduce la pulsión en representación (Repräsentanz) mediante una representación (Vorstellung). Es un poder espontáneo, condicionado pero no predeterminado, que crea el fantasma, las representaciones y los afectos. La imaginación radical está en la base del simbolismo porque gracias a ella, el ser humano puede ver una cosa en otra $(2005$, p. 239).

\section{LA IMAGEN EN EL SUEÑO}

Freud atribuyó al sueño una textura de imágenes (1979), más semejantes a percepciones que a representaciones mnémicas: el sueño alucina. Se nos ofrece la idea de un lugar psíquico, otra escena donde se forma la imagen. Ese lugar es la 
infancia del sujeto, su memoria, tiempo real. La regresión es una peculiaridad del proceso onírico: la representación queda transformada en la imagen sensible de la que nació. La regresión es aquí sinónimo de descomposición o disgregación, de ruptura de relaciones entre los pensamientos. En "La interpretación de los sueños" Freud muestra los mecanismos de conformación del sueño manifiesto a partir de fragmentos de pensamientos y mociones inconexas: condensación, desplazamiento, miramiento por la figurabilidad y elaboración secundaria (1979).

En cuanto a la interpretación, Freud reemplaza la plasticidad icónica por enunciados y pensamientos. Compara la imagen onírica con una escritura jeroglífica. Describe una forma de desplazamiento que consiste en una operación interna a la lengua por la cual se sustituye una idea latente abstracta por otra más plástica y concreta susceptible de representación en el sueño. En el sueño, la metáfora permite la figuración en imágenes. Los procedimientos de figuración no son lingüísticos sino plásticos: imágenes, diferenciaciones cualitativas, juego con las intensidades, con la puesta en escena, recorte y montaje de secuencias. Freud introduce la fantasía en la operación que da al sueño su forma definitiva: la elaboración secundaria. Con ello, la fantasía queda ligada a la representación del deseo y a su realización en el sueño. Los sueños son "puestas en escena" que expresan fantasías y la escena es la pantalla de proyección de la fantasía. Otra pantalla privilegiada para la proyección de fantasías es la creación artística. El pintor es quien sobresale en hacer "visible" su fantasma. (Oscar Pfister citado por Huot, 1991).

Cuando Freud introduce el simbolismo en el sueño, ya no hay una sustitución de la palabra con vistas a una figuración del pensamiento por medio de una imagen visual sino una traducción directa y constante del pensamiento por una imagen en una relación de símbolo.

Es así que se discriminan dos modalidades interpretativas respecto de la producción onírica: por un lado a través de las asociaciones del sujeto y por otro, la vía que abren los símbolos. La vía del simbolismo dio lugar a una modalidad de interpretación específica de los tests proyectivos: similitudes entre el cuerpo humano y la casa, figuras puntiagudas, alargadas o cavidades, bolsas, receptáculos, para referirse a los órganos sexuales, entre otros ejemplos (Hammer, 1960).

Por el contrario, el recorte que se propone articula el trabajo de la imaginación con el trabajo del sueño entendido como la transformación que sufren las ideas latentes en contenido manifiesto a través de los mecanismos de elaboración onírica.

\section{LA IMAGEN EN EL CINE}

Kristeva (2001) describe el mundo del fantasma como escenas que nos confrontan con una realidad particular, la realidad del deseo. Los fantasmas son 
producto de un psiquismo estratificado, polivalente y hojaldrado: formaciones ilusorias complejas, organismos híbridos de pasaje que juegan con la represión y el retorno de lo reprimido. La fantasmática individual reinventa los fantasmas originarios (escena primaria, castración y seducción) y modela el conjunto de la vida del sujeto, siendo la literatura y el arte lugares preferenciales para su puesta en forma verbal y pictórica. La autora se refiere a los signos visibles que designan y denuncian el fantasma como "huellas lektónicas". Los estoicos griegos distinguían el objeto real o referente de lo que llamaban "un expresable" el lekton. "que es expresión de un contrato deseante, de esa alquimia subjetiva que transforma una imagen plana (un signo denotativo) en síntoma (un especular)". (Kristeva, 2001, p. 115). Las "huellas lektónicas" son esas informaciones suplementarias: "se trata de introducir desplazamientos y condensaciones suplementarias en la imagen bruta, de asociar los tonos, ritmos, colores, figuras; en suma, de hacer jugar lo que Freud llama "procesos primarios" subyacentes a lo simbólico lo semiótico, en mi terminología - esa captura primaria de las pulsiones siempre en exceso con respecto a lo representado, a lo significado.”, (Kristeva, 2001, p. 115).

\section{LOS PROCESOS IMAGINATIVOS}

Los procesos imaginativos remiten a una construcción conceptual compleja que articula la noción de imaginación con modalidades de trabajo psíquico diversas. Intervienen en el reconocimiento de objetos, en "las imaginaciones de los neuróticos", la creación artística, la elaboración de imágenes oníricas, películas y formaciones proyectivas en general. Involucran modalidades de trabajo psíquico propias de lo originario, donde predominan aspectos alucinatorios ligados a los movimientos pulsionales primarios, hasta pensamientos que recrean las significaciones imaginarias sociales y los objetos culturales en modos propios y creativos. Como producto de la imaginación, la fantasía reelabora una actividad psíquica originaria o pictográfica (Aulagnier, 1991) que no diferencia sujetos ni discrimina el afecto de la representación (Green, 1999). Es un "afecto representativo" figura monádica que articula huellas erógenas y sensoriales y constituye un fondo permanente que dinamiza la productividad psíquica a partir de la imposición de separación del objeto que, sin embargo, no induce el reconocimiento del espacio exterior como prueba del principio de realidad sino la elaboración de fantasías acerca del espacio exterior. Cuando las representaciones de cosa se ligan a las representaciones de palabra se organizan las fantasías en guiones que adquieren mayor estabilidad. En un principio los lugares son intercambiables y el sentido remite a la relación. Pero luego en la escena se van diferenciando sujeto, objeto y una relación entre ambos. En un principio, también las palabras llevarán la carga de lo primario. A medida en que se van produciendo procesos de diferenciación se discriminan afectos y representaciones y se distribuyen los investimientos. Las 
fantasías como formaciones del preconsciente se distancian de las representaciones cosa más ligadas a lo arcaico fijadas como núcleo del inconsciente a partir de que la represión se estabiliza. En el proceso secundario, las formas de organización del psiquismo implican la incorporación del posicionamiento del semejante, la causalidad, la temporalidad y las representaciones espaciales con un activo acceso a los códigos sociales que permite la incorporación de la herencia cultural. Las mociones deseantes propulsivas de la búsqueda de objetos de investimiento y la posibilidad de desinvertir objetos o partes de objetos para incorporar novedades se nutren de la oferta de objetos sociales existente. Se inscribe la diferencia y el entramado discursivo se complejiza por la adscripción a las significaciones imaginarias sociales. En su modalidad más sofisticada, la imaginación metafórica, articula imagen y sentido produciendo un orden semántico nuevo, combinando lo verbal con lo no verbal y confrontando un sentido literal con uno figurativo.

\section{LA PRODUCCIÓN GRÁFICA}

El dibujo puede considerarse el resultado de procesos motores, cognitivos y emocionales que intervienen en su producción. Cada uno de estos procesos admite interpretaciones diversas y por eso ha sido estudiado desde múltiples perspectivas y referencias teóricas. Las lecturas evolutivas, psicométricas, clínicas y proyectivas han dado lugar a la construcción de objetos con criterios de lectura basados tanto en el análisis de los contenidos como de las características formales, con frecuentes intersecciones entre ambos campos (Bombi, 1998).

El análisis semiótico de las imágenes materiales visuales diferencia imágenes plásticas, simbólicas y figurativas. (Magariños de Morentín, 2001). Estas categorías constituyen una base empírica metodológica que, perteneciendo a una disciplina externa, resultan de utilidad por sus enlaces posibles con las dimensiones psíquicas de los procesos imaginativos.

Los aspectos plásticos, que remiten a lo que Magariños llama "elemento dinámico", o "lo cualitativo" puede estar o no integrado en elementos figurales y simbólicos. Se relaciona con la perspectiva escritural propuesta por Marisa Rodulfo (1993): el dibujo como escritura en imágenes alude a la umbilicación del trazo en el cuerpo a través de la grafo-motricidad. También se vincula con lo que Kristeva denomina "lo semiótico", lo pulsional no representado en términos especulares, no captado por las fantasmas y sus derivas de sentido. Sami Ali (1976) se refiere a "los esquemas motores del graficar". Cuando no está integrado, el afecto se revela como proceso de descarga (elementos pictogramáticos, mixto indisociable afecto-representación) o por su ausencia. Los "quale" o aspectos plásticos tienen menor eficacia simbólica que los aspectos figurativos y simbólicos porque se trata de indicios o índices que requieren para su interpretación de su remisión a la 
semiosis privada del íntérprete. Constituyen el umbral mínimo en el proceso de elaboración de sentido De modo que en los gráficos hay trazos motores y trazos simbólico-figurativos. Se trata de un continuum donde encontramos dibujos más pulsionalizados, dibujos donde predominan los procesos primarios, dibujos donde los procesos primarios se ordenan a través del uso de significantes gráficos, y dibujos donde predominan los significantes gráficos vacíos de elementos dinámicos.

La figuración está ligada al control de la impulsividad que se evidencia en los aspectos grafo-plásticos. La calidad de los aspectos figurativos depende de la disponibilidad y el uso de significantes gráficos. Diferenciamos el realismo fortuito, el realismo simbólico o intelectual, y el realismo visual (Luquet (1927). El realismo visual responde a la intencionalidad de copia, al intento de producir un efecto visual similar al que nos produce la realidad representada. Mientras más similar sea el efecto, más icónica será la representación. En el extremo opuesto, está la abstracción, que supone que la imagen no tiene parecido con una realidad concreta, puede ser producto de la fantasía (imágenes surrealistas) o relaciones arbitrarias. En el análisis de los aspectos figurativos, la máxima sencillez está dada por las figuras "cliché" o estereotipos. Un "tipo" o estereotipo, formula o esquema es la representación que un niño determinado da de un mismo objeto o motivo a través de sucesivos dibujos (Luquet, 1927).Se trata de la representación canónica de los objetos. (Baldy, p. 52). Son representaciones estándar, esquemáticas, prototípicas del género de objetos del tema. Es lo opuesto a una representación densa semánticamente (Van Sommers, 1984). La complejidad se expresa en las "marcas de identidad" de las figuras, el código espacial utilizado, la escenografía y demás elementos figurativos, que adquieren eficacia simbólica. En las figuras humanas encontramos marcas gráficas de la edad, el sexo, vestimenta, elementos de diferenciación. Las desproporciones significativas son distorsiones que dan cuenta de la implicación afectiva que otorga complejidad a la producción (densidad semántica). La función simbólica agrega a un significado básico y directo (icónico) otro indirecto. Las creaciones simbólicas novedosas requieren para ser develadas, las asociaciones orales o aspectos de la biografía del sujeto. Warnock habla en este caso de símbolos "legítimos" comparables a metáforas (Warnock, 1994). Lo figurativo muestra una analogía concreta, icónica, con un existente y la operación en juego no es la interpretación sino el reconocimiento de las imágenes. En cambio, lo simbólico agrega a lo figurativo un sentido adicional a interpretar. Una imagen que tuviera una única representación de un objeto o que no pudiera vincularse a otra representación, actividad u objeto externo a esa imagen, o sea, una imagen sin relaciones sintácticas internas o externas a la propia imagen, o sin distorsiones retóricas, no sería nunca una imagen simbólica, porque no construiría significación alguna. Por lo tanto, no es interpretable. Los teóricos de la Ilustración han 
definido a las figuras retóricas visuales como una transgresión simulada de una norma (Mazzeo, C y Fridman, G, 2014). Son procedimientos gráficos para expresar relaciones de sentido: acentuación, anacoluto, hipérbole, metáfora, metonimia, hipérbole, sinécdoque, personificación, enganche, repetición, acumulación, elipsis. Estos procedimientos alejan las imágenes de la plasticidad icónica y la dotan de índices subjetivos o "huellas lektónicas" que expresan relaciones de sentido.

Respecto de la interpretación, las imágenes visuales no son autosuficientes para interpretarse en sí mismas. Las palabras no están, en las imágenes simbólicas, ni antes ni después del dibujo sino que están eficazmente reemplazadas por el dibujo (en cuanto expresivo de lo que, de otro modo, sería indecible). Sin embargo, las asociaciones orales y escritas aportan claves para la interpretación. En el encuadre clínico, las dimensiones plástica, figurativa, simbólica y verbal quedan subordinadas a la intención relacional marcada por los aspectos transferenciales. La afectividad comanda la producción: lo que el niño dibuja es la figuración, de aquello que en el encuentro con el terapeuta se activa de su historia libidinal.

Para interpretar las imágenes simbólicas, la semiosis psicoanalítica aporta como esquemas básicos los fantasmas originarios. Las imágenes se constituyen como "análogos narcisistas" (Sami Ali, 1976), como proyección de la imagen inconsciente del cuerpo (Dolto, 1986), como despliegue de fantasmas (Kristeva, 2001) y como escenificación de conflictivas (Wald, 2015) .

\section{ANÁLISIS DE LOS CASOS}

El modelo de análisis permite un análisis clínico singular ya que, a partir de la consigna gráfica, cada dibujo articula los aspectos plásticos, figurativos, simbólicos y verbales en una propuesta semántica propia.

En todos los casos, se recupera el dinamismo que está en la base de la modalidad productiva, pero solo en los casos de niños que incorporan en sus dibujos aspectos simbólicos y /o verbales es posible interpretar los ejes de sentido

\footnotetext{
4 La matriz teórica en la que se enmarca el análisis emplaza el campo de producción de la subjetividad infantil en una línea de intersubjetividad en la cual se definen los ejes históricos de sentido subjetivo frente a los cuales, sin embargo, el niño no es pasivo. La complejización creciente de las estructuras psíquicas implica modos de elaboración a partir de una metabolización compleja y heterocrónica de derroteros pulsionales, afectivos e identificatorios con los objetos primarios de investidura que incluye el campo social.
} 
subjetivo e histórico asociados en cada niño a los obstáculos en sus procesos de aprendizaje.

A partir del análisis del conjunto de los casos, se describen dinámicas a partir del entramado del afecto que se articula en los aspectos plásticos, la complejidad figurativa (calidad de representación a través de significantes gráficos), la complejidad simbólica (incorporación de sentidos interpretables) y las posibilidades asociativas verbales.

En la mayoría de los dibujos analizados el afecto no está integrado a la dinámica productiva. Podemos describir una primera modalidad, donde nos encontramos con dibujos con buena complejidad figurativa, pero se trata de imágenes-copia, figuras cliché, sin distorsiones retóricas ni sintaxis gráfica. Cuando la intencionalidad figurativa responde a la producción de imágenes copia de referentes concretos, el trabajo de la imaginación es suplantado por formas vacías, sobreadaptadas y carentes de las energías semióticas del cuerpo pulsante. Esto ocurre independientemente de la complejidad de la producción desde el punto de vista figurativo. Lo que está ausente es la complejidad semántica que remite a niveles de sentido inconsciente que dependen de los mecanismos de elaboración onírica para ser figurados. La elaboración secundaria no trabaja en relación con los procesos primarios sino con la investidura orientada a la percepción externa "realista". Es decir que independientemente de la riqueza figurativa, las producciones no muestran funcionalidad de los procesos proyectivos, ya sea como resultado de una insuficiencia en el trabajo representativo o de una intensa contrainvestidura frente a contenidos psíquicos que se activan en la situación transferencial. Es por ello que, si el mecanismo de contrainvestidura fracasa, las imágenes cliché pueden coexistir en el mismo dibujo con trazos motores producto de procesos evacuativos.

Otras modalidades presentan contenidos simbólicos (análogos narcisistas, escenas y fantasías) producto de la elaboración proyectiva, pero aparecen disrupciones o quiebres que pueden responder tanto a expulsiones pulsionales como a procesos fantasmáticos con menor o mayor grado de organización. Se trata de dibujos que pueden presentar cierta complejidad simbólica y figural pero pierden calidad y transmisibilidad por los quiebres que fragmentan las producciones. Las disrupciones aparecen en acciones, gestos, trazos motores o en imágenes poco legibles pero cargadas semánticamente y se vinculan con aspectos conflictivos. En estos casos se establece el proceso proyectivo en imágenes y palabras pero aparecen disrupciones de los procesos primarios que desorganizan las producciones tanto gráficas como verbales. Aquí la insuficiencia se encuentra en la labor de mediación del preconsciente para filtrar los fantasmas y otorgarles expresión fi- 
gural u ordenamientos verbales. El preconsciente implica una formalización que incorpora recursos lingüísticos, culturales, y gráficos. Cuando la represión se opone a la cooperación entre los sistemas psíquicos, las representaciones de cosa, apenas articuladas como fantasías, proliferan sin el ordenamiento preconsciente y producen desbordes en las producciones.

En el límite, los quiebres se vinculan con una discriminación insuficiente entre procesos secundarios y procesos primarios. En estos casos, los significantes gráficos y verbales están enlazados a través de condensaciones y desplazamientos sin la formalización de la organización preconsciente. Cuando el encuadre clínico activa un modo de funcionamiento desorganizado y poco discriminado se evidencian fallas en la disponibilidad de recursos del ordenamiento preconsciente. Predominan en algunos casos los procesos evacuativos con escasos elementos figurativos.

Las producciones que podríamos llamar "imaginativas" articulan aspectos plásticos, figurativos y simbólicos en una propuesta gráfica que abre a ejes de sentido. Las imágenes están cargadas de significación a través de rasgos semióticos formales, plástico-figurativos (figuras retóricas visuales) y/o a través de una sintaxis gráfica. La interpretación se aleja de la plasticidad icónica de las imágenes para atender a líneas de sentido en relación a los rasgos semióticos extralingüísticos: atributos, tamaño, características en general, y también la organización de la espacialidad gráfica. Son imágenes metafóricas que, a la vez que enmascaran, integran múltiples y complejos niveles de sentido. El afecto está articulado en la elaboración representativa a través de cualidades y atributos de las imágenes. Los mecanismos de condensación y desplazamiento otorgan características subjetivas a las figuras que, a la manera de restos diurnos, sirven a la elaboración secundaria para crear escenas, análogos narcisistas, narraciones gráficas y/o ficcionales, que pueden ser interpretados con el método de interpretación de los sueños, es decir, apelando a las asociaciones del dibujante. La creación de nuevas figuras gráficas asociadas a viejos motivos o temas según la lógica del retorno y la composición son producciones realizadas en regresión transferencial, donde la hoja en blanco se constituye como pantalla proyectiva. De este modo, las imágenes constituyen objetos trans-narcisistas que permiten a los niños representar aspectos fantasmáticos e identificatorios y aun sus conflictos restrictivos. La dimensión transnarcisista se sostiene en que el terapeuta puede gozar por identificación con el niño creador a partir del placer estético que las imágenes comportan (Green, 2001). Se trata de un "decir", de un "mostrar" más allá de la plasticidad icónica de la imágenes a través de una eficacia simbólica, metafórica, que moviliza múltiples niveles de sentido.

A continuación, se presenta el modelo de análisis. 
Cuadro 1 Modelo de análisis empleado.

\begin{tabular}{|c|c|c|c|}
\hline Categorías & Indicadores & $\begin{array}{l}\text { Dinámica de las } \\
\text { representaciones }\end{array}$ & $\begin{array}{l}\text { Complejidad de la } \\
\text { propuesta semántica }\end{array}$ \\
\hline $\begin{array}{l}\text { Aspectos } \\
\text { plásticos }\end{array}$ & $\begin{array}{l}\text { —-Signos Plásticos: manchas, } \\
\text { garabatos, rayas, clima } \\
\text { emocional, vacío, llenado. } \\
\text { —Aspectos grafo- motores: } \\
\text { tipo de trazo, motricidad, } \\
\text { desplazamientos, frenado, } \\
\text { velocidad, rigidez. } \\
\text { —Intencionalidad previa } \\
\text { a la acción, en acción o } \\
\text { secundaria. }\end{array}$ & $\begin{array}{l}\text { Dinámica del afecto en } \\
\text { formas pcitogramáticas } \\
\text { y escenas. Predominio de } \\
\text { funcionamiento evacuativo, } \\
\text { ligado en imágenes o } \\
\text { ausencia de afecto. }\end{array}$ & $\begin{array}{l}\text { Umbral básico de sentido } \\
\text { a través de "quale" } \\
\text { que articulan aspectos } \\
\text { pulsionales y narcisistas. }\end{array}$ \\
\hline $\begin{array}{l}\text { Aspectos } \\
\text { figurativos }\end{array}$ & $\begin{array}{l}\text { —Intencionalidad figurativa: } \\
\text { realismo visual, intelectual, } \\
\text { clichés, invenciones. } \\
\text { —Calidad y complejidad de } \\
\text { la representación plástica, } \\
\text { sencillez, complejidad, } \\
\text { originalidad. } \\
\text { —Aspectos formales de las } \\
\text { figuras: tamaño, orientación, } \\
\text { inclusión u omisión } \\
\text { de partes del cuerpo, } \\
\text { proporción, integración. }\end{array}$ & $\begin{array}{l}\text { Complejidad del } \\
\text { preconsciente en la dinámica } \\
\text { de las representaciones } \\
\text { plásticas y en la elaboración } \\
\text { secundaria que permite } \\
\text { el filtrado de escenas y } \\
\text { fantasías. }\end{array}$ & $\begin{array}{l}\text { Calidad del contenido } \\
\text { manifiesto de la } \\
\text { composición figural. }\end{array}$ \\
\hline $\begin{array}{l}\text { Aspectos } \\
\text { simbólicos }\end{array}$ & $\begin{array}{l}\text { —Sintaxis gráfica: temas. } \\
\text { —-Figuras retóricas visuales. }\end{array}$ & $\begin{array}{l}\text { Presencia o ausencia } \\
\text { de escenas y fantasías } \\
\text { a partir de mecanismos } \\
\text { inconscientes: } \\
\text { condensación, } \\
\text { desplazamiento, cuidado por } \\
\text { la figurabilidad, elaboración } \\
\text { secundaria. }\end{array}$ & $\begin{array}{l}\text { Proyección de contenidos: } \\
\text { análogos narcisistas, } \\
\text { fantasías, conflictos. }\end{array}$ \\
\hline $\begin{array}{l}\text { Aspectos } \\
\text { verbales }\end{array}$ & $\begin{array}{l}\text { —Verbalizaciones orales: } \\
\text { descripciones o asociaciones } \\
\text { significativas. } \\
\text { —Escritura: Características } \\
\text { expresivas del relato, } \\
\text { ausencia, descripción, } \\
\text { creación ficcional. } \\
\text { —Organización lógica } \\
\text { y sintáctica. Quiebres } \\
\text { puntuales. }\end{array}$ & $\begin{array}{l}\text { Narración como } \\
\text { organización preconsciente } \\
\text { que reconstruye ejes de } \\
\text { sentido proyectados en las } \\
\text { imágenes. Implica aspectos } \\
\text { dinámicos de conectividad } \\
\text { entre pictogramas, escenas } \\
\text { y fantasías. }\end{array}$ & $\begin{array}{l}\text { Interpretación narrativa de } \\
\text { las imágenes proyectivas } \\
\text { en una secuencia lógico- } \\
\text { sintáctica que aporta nuevos } \\
\text { contenidos. }\end{array}$ \\
\hline $\begin{array}{l}\text { Aspectos } \\
\text { relacionales }\end{array}$ & $\begin{array}{l}\text { —Modo de vinculación con } \\
\text { el terapeuta: colaboración, } \\
\text { reticencia, falta de distancia, } \\
\text { signos de angustia etc. }\end{array}$ & $\begin{array}{l}\text { La activación transferencial } \\
\text { interviene en escenas, } \\
\text { fantasías, y formas } \\
\text { pictogramáticas. }\end{array}$ & $\begin{array}{l}\text { Actualización de sentidos } \\
\text { históricos aspectos } \\
\text { dinámicos. }\end{array}$ \\
\hline
\end{tabular}

Fonte: Elaborado por la autora. 


\section{IMPACTO DEL MODELO EN LA TEORÍA DE LOS PROCESOS IMAGINATIVOS}

El mecanismo psíquico central en los procesos imaginativos tanto en las producciones con contenidos proyectivos como en los contenidos cognoscitivos es la elaboración secundaria. La elaboración secundaria, está presente tanto en el sueño como en la percepción y en la proyección y obedece a una preocupación de coherencia e inteligibilidad. Como actividad interpretativa en la percepción implica la aplicación de un saber que permite "situar al objeto en el espacio y en el tiempo, investirlo de un sentido que parece habitarlo, y conferirle una coloración afectiva que lo pone en contacto con un pasado inmemorial" (Sami Ali, 1982, p. 89). En el encuadre clínico, la producción proyectiva propiamente dicha involucra la puesta en relación de representaciones cosa y representaciones palabra elaborando una producción que sustituye significativamente la experiencia transferencial, permitiendo al sujeto el desconocimiento respecto de sí mismo. La elaboración secundaria elige los significantes gráficos que servirán a la formación de una figura particular que dejará filtrar por sustituciones y alusiones un contenido. Luego esas imágenes se destacan por su valor afectivo y por transformaciones retóricas que las vuelven llamativas en tanto soporte de proyecciones con un sentido descifrable. La producción, es entonces resultado de la elaboración secundaria a la que están sometidas todas las actividades perceptivas e imaginarias.

De este modo, no todo dibujo realizado en el encuadre clínico es proyectivo. A partir de una concepción ampliada de la proyección entendida como modalidad de externalización de los procesos psíquicos internos, marcados con el sello de su origen pulsional e inconsciente (Green, 2001), habría diversas modalidades de vínculo con el objeto cuyo umbral básico es el proceso de excorporación pulsional y su límite es la incorporación de las diferencias.

El dibujo proyectivo puede comparase con una escritura plástica y la interpretación es su traducción a la lengua hablada por el sujeto. Los procedimientos de figuración, obra de la imaginación metafórica, no son lingüísticos sino plásticos: imágenes, diferenciaciones cualitativas entre estas, juego con las intensidades y con la puesta en escena, recorte y montaje de secuencias.

\section{SIMBOLIZACIÓN, PROCESOS IMAGINATIVOS Y APRENDIZAJE}

Nos movemos en un contínuo entre símbolos transparentes que leemos en forma automática en un extremo (signos), y símbolos que requieren para su comprensión del uso de la imaginación. En el nivel de la interpretación, el contínuo va desde la interpretación necesaria y automática a la captación imaginativa de ver una cosa como otra. Estos símbolos "legítimos" son comparables a metáforas (Warnock, 1994). Hay un uso de símbolos transparentes, unívocos, e icónicos, aprendidos por aprendizaje de una convención que constituyen semiosis institui- 
das, y un uso imaginativo de los símbolos que involucra fundamentalmente la imaginación metafórica.

El modelo propuesto se orienta al análisis de los procesos imaginativos en el uso de símbolos. En este sentido podemos decir que todos los niños simbolizan, pero las características de sus producciones simbólicas dependen de los procesos imaginativos que les otorgan sentido singular. La imaginación metafórica que produce simbolizaciones que filtran contenidos inconscientes requiere del mecanismo de elaboración secundaria que se vincula tanto con los procesos primarios como con el proceso secundario y la censura. Implica tanto la disponibilidad y movilidad de huellas como de recursos lógicos, semánticos y sintácticos del preconsciente para crear propuestas semánticas novedosas.

En el caso de las producciones gráficas realizadas en el encuadre clínico, la eficacia máxima de los procesos imaginativos se despliega cuando la producción se aleja tanto de la plasticidad icónica de las imágenes como de los procesos de expulsión afectiva para aludir a través de formaciones plásticas singulares e inteligibles a guiones fantasmáticos y narcisistas del sujeto.

Así, las producciones simbólicas gráficas con características imaginativas constituyen formas proyectivas productos de la sublimación, que implican un tratamiento particular de los objetos simbólicos, una condensación de la fuerza pulsional y el narcisismo del creador en una formalización estética.

Los procesos imaginativos participan tanto en la elaboración imaginaria como en la apropiación simbólica de objetos culturales. Ambas dimensiones implican la articulación de procesos psíquicos heterogéneos y su entramado en la historia libidinal e identificatoria del sujeto pero se diferencian respecto de la orientación libidinal narcisista u objetal. En un caso, predomina la realización de deseos, que sin embargo requiere de los enclaves preconscientes para desplegarse de modos plásticos y creativos, y en el otro el aprendizaje por la experiencia. La diferencia radica en la predominancia de aspectos narcisistas y proyectivos en un caso y del reconocimiento de las significaciones sociales de los objetos en el otro. El mecanismo de elaboración secundaria siempre está en continuidad con la historia libidinal, pero puede orientarse predominantemente a la percepción o a la proyección. En el conocimiento, las experiencias con los objetos tienen un valor interrogativo, cuestionan las certidumbres tendientes a la satisfacción narcisista. Un intercambio que tenga en cuenta la diferencia, se constituye con objetos que no estén totalmente marcados por el sello del narcisismo del sujeto.

Para finalizar, una referencia a los usos clínicos del modelo de análisis. Consideramos que es una herramienta diagnóstica tanto para la construcción de hipótesis clínicas que orientan las intervenciones terapéuticas durante el tratamiento, como para la evaluación de las transformaciones de las producciones y de los procesos psíquicos involucrados durante el proceso terapéutico. 


\section{REFERENCIAS}

Aulagnier, P. (1991). La violencia de la interpretación. Buenos Aires, Amorrortu.

Baldy, R. (2008) Dessine-moi un bonhomme. Dessins d'enfants et développement cognitif. [Dibújame una figura humana. Dibujos de los niños y desarrollo cognitivo]. Paris: Éditions in Press.

Bombi, A y Pinto, G. (1998) Los colores de la amistad. Estudios sobre las representaciones pictóricas de la amistad entre los niños. Madrid: Visor

Burns,R.C. y Kaufman, S.H. (1978): Los dibujos kinéticos de la familia como técnica psicodiagnóstica. Buenos Aires: Paidós.

Castoriadis, C. (2005). Figuras de lo pensable. Buenos Aires: Editorial FCE.

Dolto, F. (1986). La imagen inconsciente del cuerpo. Barcelona, España, Paidós.

Freud, S. (1979). La interpretación de los sueños. En J. Strachey (Ed.) Obras Completas de Sigmund Freud. (Vol. V). Buenos Aires: Amorrortu. (Trabajo original publicado 1900).

Gonzalez Rey, F. (2006). Investigación cualitativa y subjetividad. Guatemala: Oficina de derechos humanos del arzobispado de Guatemala.

Green, A. (1999). Sobre la discriminación e indiscriminación afecto-representación. Revista de psicoanálisis de la Asociación Psicoanalitica Argentina. Tomo LVI, n. 1. p. 11-71 Buenos Aires: Nueva Visión.

Green, A. (2001). Mythes et realités sur le processus psychanalytique. Revue Francaise de Psychosomatique 19 y 20.

Hammer, E. (1960). Tests proyectivos gráficos. Buenos Aires: Paidos.

Huot, H.(1991). Del sujeto en la imagen. Una teoría del ojo en la obra de Freud. Buenos Aires: Nueva Visión.

Kearney, R. (1998). The Poetics of Imagining. Modern to Postmodern. [La poética de la imaginación. Moderna a Posmoderna]. New York, Fordham University Press.

Kristeva, J. (2001). La revuelta intima. Literatura y psicoanálisis. Buenos Aires: Eudeba.

Kristeva, J. (1997). Sol negro, depresión y melancolía. Venezuela: Monte Ávila Editores Latinoamericana.

Luquet, G. (1927). Le dessin s d'un enfant: étude psychologique. [El dibujo de un niño. Estudio psicológico]. Paris: Alcan.

Magariños de Morentin, J. (2001). La(s) semiótica(s) de la imagen visual. Revista Cuadernos, n. 17, de la Facultad de Humanidades y Ciencias Sociales de la Universidad Nacional de Jujuy (p. 295-320). Jujuy, Argentina. Recuperado de http://www.archivo-semiotica.com.ar/vision.html\#LA(S).

Mazzeo, C y Fridman, G. Introducción a la retórica visual. Diseño Gráfico 1. Cátedra Mazzeo. FADU/UBA. Recuperado de http://www.cmazzeo.com.ar/dg/downloads/d1/ retorica.pdf

Ricoeur, P. (2010). Del texto a la acción. Ensayos de hermenéutica II. Buenos Aires: Fondo de Cultura Económica. 
Rodulfo, M. (1993). El niño del dibujo. Buenos Aires, Paidós.

Sami-Ali, M. (1976). El espacio imaginario. Buenos Aires: Amorrortu.

Sami Ali, M. (1982). De la proyección. Madrid: Petrel.

Schlemenson, S. (2010). Procesos de Simbolización y Transformaciones psíquicas durante el Tratamiento Psicopedagógico. Presentación de un modelo teórico-clínico en Anuario de Investig. vol.17 Ciudad Autónoma de Buenos Aires ene./dic. 2010, 191-98.

Stiles Stiles, W.B. (2009). "Logical operations in Theory-Building Case Studies". En Pragmatic Case Studies in Psychotherapy, Vol5, Module 3, Article 2. 9-22.

Van Sommers,P. (1984) Drawing and cognition: Descriptive and experimental studies of graphic production processes. New York, NY, US: Cambridge University Press.

Vigotsky, L. (2003). Imaginación y creación en la edad infantil. Buenos Aires: Nuestra América.

Wald, A. (2015). Los procesos imaginativos en la producción gráfica de niños con problemas de aprendizaje. Tesis de Doctorado. Facultad de Psicología. Universidad de Buenos Aires.

Warnock, M (1994) Imagination and Time. [Imaginación y Tiempo]. Oxford U.K: Blackwell Publishers. 